\title{
NILAI EKONOMI WISATA PEMANDIAN AIR PANAS WALINI CIWIDEY KABUPATEN BANDUNG JAWA BARAT
}

\section{Economic Value Of Walini Hot Springs Tourism Ciwidey Bandung Regency Of West Jawa}

\author{
Anadilla Fahyra Riawan ${ }^{1)}$, Endah Djuwendah ${ }^{2)}$, Sulistyodewi Nur Wiyono ${ }^{3)}$, dan Ernah ${ }^{4)}$ \\ 1,2,3,4) Departemen Sosial Ekonomi Pertanian, Fakultas Pertanian, Universitas Padjadjaran \\ Email: ernah@unpad.ac.id, lalaafr@gmail.com
}

Submit: 10 Agustus 2020, Revised: 6 Agustus 2020, Accepted: Agustus 2020

\begin{abstract}
Tourism sector is one of the solutions to help increase economic activity and country's foreign exchange, the welfare of local communities and the image of Indonesia. Of the tourist attractions that have been increasing every year in Indonesia is Walini hot spring which utilizes its natural resources as attractions and located in West Jawa. The economic market value of utilizing the potential natural resources as attraction is unknown. This research aims were to determine the characteristic of tourists and the estimated economic value of Walini Hot Springs, Ciwidey, Bandung Regency, West Java using descriptive statistic analysis. The majority of the tourists were between the ages $41-50$ years who worked as private employees and come with family. The visit frequency was significantly influenced by the distance from their residence and group size. The consumer and the economic surplus of the Walini Hot Spring were IDR 4,536,424 and IDR 6,394,456,922, respectively. The magnitude of this economic surplus shows that the tourists are still interested in maintaining the existence of Walini Hot Springs attractions. Hence, the manager should improve the existing facilities so that the tourists feel comfortable and safe when visiting.
\end{abstract}

\section{Keywords: Ciwidey; Economic Surplus; Travel Cost Method and Tourism.}

\section{ABSTRAK}

Sektor pariwisata merupakan salah satu potensi yang dapat membantu meningkatkan aktivitas ekonomi dan meningkatkan devisa negara, kesejahteraan masyarakat lokal dan citra Indonesia. Dalam beberapa tahun terakhir, pembangunan pariwisata di seluruh dunia terutama di Indonesia terus mengalami peningkatan dan diharapkan dapat menjadi penghasil devisa nomor satu agar dapat menjadi salah satu solusi pembangunan ekonomi di Indonesia.Salah satu jenis pariwisata yang berpotensi yaitu pariwisata yang memanfaatkan sumber daya alam adalah Pemandian Air Panas Walini. Objek wisata yang memanfaatkan potensi sumber daya alam memiliki nilai ekonomi yang tidak diketahui besaran nilai pasarnya. Penelitian ini bertujuan mengetahui karakteristik wisatawan dan mengetahui estimasi nilai ekonomi Pemandian Air Panas Walini, Ciwidey, Kabupaten Bandung, Jawa Barat. Penelitian ini menggunakan desain kuantitatif dengan metode statistik deskriptif untuk menggambarkan karakteristik wisatawan dan metode biaya perjalanan untuk mengestimasi nilai ekonomi. Hasil penelitian ini menunjukkan bahwa mayoritas responden berusia 41-50 tahun, bekerja sebagai pegawai swasta, dan datang bersama keluarga. Faktor jarak tempat tinggal dan jumlah rombongan adalah faktor-faktor yang berpengaruh signifikan terhadap frekuensi kunjungan. Nilai surplus konsumen dan nilai ekonomi Pemandian Air Panas Walini masing-masing adalah Rp 
4.536.424,- dan Rp 6.394.456.922,-. Besarnya nilai ekonomi ini menunjukkan bahwa wisatawan masih tertarik untuk mempertahankan keberadaan objek wisata Mata Air Panas Walini. Oleh karena itu, manajer harus meningkatkan fasilitas yang ada sehingga wisatawan merasa nyaman dan aman saat bepergian.

Kata Kunci: Ciwidey; Metode Biaya Perjalanan; Nilai Ekonomi dan Wisata.

\section{PENDAHULUAN}

Perkembangan sektor pariwisata akan membantu meningkatkan kegitan ekonomi suatu negara serta meningkatkan devisa negara, kesejahteraan masyarakat lokal dan citra Indonesia. Dalam beberapa tahun terakhir, pembangunan pariwisata di seluruh dunia terutama di Indonesia terus mengalami peningkatan dan diharapkan dapat menjadi penghasil devisa nomor satu agar dapat menjadi salah satu solusi pembangunan ekonomi di Indonesia.

Kontribusi sektor pariwisata terhadap perolehan devisa negara terus mengalami peningkatan setiap tahunnya. Pada tahun 2018, besar pendapatan devisa dari sektor pariwisata mencapai US\$ 16,1 miliar atau sekitar Rp 228 triliun. Salah satu faktor meningkatnya angka pendapatan devisa negara ini dikarenakan terus meningkatnya jumlah wisatawan yang melakukan kegiatan pariwisata di Indonesia, baik wisatawan mancanegara maupun wisatawan nusantara. Bahkan pada tahun 2018, jumlah wisatawan mancanegara yang melakukan kegiatan pariwisata mencapai angka 303 juta orang dan jumlah wisatawan nusantaranya sendiri mencapai angka 17 juta orang. Meningkatnya jumlah wisatawan akan meningkatkan rata-rata pengeluaran kunjungan wisatawan per perjalanan yang dilakukan.

Jumlah wisatawan yang melakukan kegiatan pariwisata di Indonesia terus meningkat karena teknologi dan informasi pariwisata nasional terus berkembang. Wisatawan dari berbagai daerah dan negara dapat dengan mudah memperoleh informasi terkait pariwisata di Indonesia. Dukungan fasilitas dan destinasi objek daya tarik wisata di Indonesia juga terus mengalami peningkatan dan perkembangan. Peningkatan jumlah objek daya tarik wisata di Provinsi Jawa Barat terus terjadi dari tahun ke tahun. Jumlah objek wisata yang berada di Jawa Barat adalah 1.480 dengan rata-rata kunjungan wisatawan nusantara mencapai 40 - 50 juta orang per tahun sementara tingkat kunjungan wisatawan mancanegara mencapai 2 juta orang per tahun (Dinas Pariwisata dan Kebudayaan Provinsi Jawa Barat, 2018)

Meningkatnya jumlah objek wisata dan wisatawan juga mendorong diterapkannya pariwisata berkelanjutan (sustainable tourism) di mana industri pariwisata berbasis pada perlindungan sumber daya alam dan lingkungan yang berperan sebagai penyumbang jasa kegiatan wisata. Salah satu daerah di Provinsi Jawa Barat yang dikenal dengan objek wisata berbasis perlindungan sumber daya alam dan lingkungannya adalah Kabupaten Bandung.

Kecamatan Ciwidey merupakan salah satu kecamatan di Kabupaten Bandung yang memiliki banyak daya tarik wisata. Salah satu di antaranya yang cukup dikenal yaitu Pemandian Air Panas Walini. Pemandian Air Panas Walini dikelola oleh Puskopkar (Pusat Koperasi Karyawan PTPN VIII) yang didirikan pada tahun 1993. Objek wisata ini berada di ketinggian 1700 mdpl dengan atmosfer tenang dan udaranya yang sejuk. Potensi alam pada Pemandian Air Panas Walini pastinya dapat menarik minat para wisatawan. Keberadaan Pemandian Air Panas Walini tentu menimbulkan aktivitas ekonomi seperti adanya tiket masuk seharga Rp 20.000, - per wisatawan. Aktivitas ekonomi akan terjadi baik di dalam objek wisata ataupun di luar objek wisata. Tetapi, objek wisata Pemandian Air Panas Walini memiliki nilai pasar yang tidak diketahui. Hal ini dikarenakan objek wisata ini memanfaatkan kekayaan alam yang tidak diketahui besaran nilai pasarnya. 
Nilai ekonomi yang dapat diperoleh dari pemanfaatan Pemandian Air Panas Walini sebagai objek wisata sampai saat ini belum diketahui. Nilai ekonomi yang akan dicari tidak hanya dinilai dari jumlah wisatawan yang datang dan dari jumlah tiket yang terjual saja, tetapi estimasinya dapat ditemukan menggunakan berbagai pendekatan. Pendekatan dapat digunakan untuk memperkirakan estimasi besarnya permintaan, manfaat, dan surplus konsumen. Pendekatan yang digunakan pada penelitian ini adalah pendekatan biaya perjalanan. Biaya perjalanan yang dikeluarkan dan faktor-faktor yang mempengaruhi frekuensi kedatangan wisatawan Pemandian Air Panas Walini juga perlu diketahui guna mengestimasi nilai ekonomi. Penilaian ekonomi ini sendiri dibutuhkan oleh objek wisata Pemandian Air Panas Walini guna mengetahui besaran nilai ekonomi yang dihasilkan dari pemanfaatan sumberdaya objek wisata ini.

\section{METODE PENELITIAN}

Penelitian ini dilakukan pada bulan Desember 2019 - Januari 2020 di Pemandian Air Panas WaliniCiwidey, Kabupaten Bandung, Provinsi Jawa Barat. Desain penelitian ini menggunakan pendekatan penelitian kuantitatif (Reynaltodan Ernah, 2019). Teknik penelitian yang digunakan oleh penulis adalah metode survey. Pengumpulan data dilakukan dengan melakukan wawancara, kuesioner (angket), dan studi pustaka.

Data pada penelitian ini dianalisis dengan menggunakan analisis deskriptif (Amalia dan Ernah, 2017). Analisis deskriptif digunakan untuk menggambarkan karakteristik wisatawan. Nilai ekonomi akan diestimasikan melalui pendekatan biaya perjalanan. Pendekatan biaya perjalanan digunakan karena relatif lebih mudah dan cepat untuk dilakukan, selain itu pendekatan ini juga menganalisis penilaian responden atas penilaian atas suatu tempat.

Metode biaya perjalanan akan dibuat dalam bentuk fungsi permintaan dengan beberapa faktor sosial ekonomi yang mempengaruhinya. Dari fungsi permintaan akan ditemukan koefisien biaya perjalanan yang diperlukan untuk menentukan surplus konsumen per individu per kunjungan. Estimasi nilai ekonomi objek wisata dilakukan dengan mengalikan surplus konsumen dan jumlah pengunjung Pemandian Air Panas Walini per tahun.

$$
\text { Pengambilan sampel yang }
$$
digunakan dalam penelitian ini adalah purposive sampling. Penentuan jumlah sampel yang diteliti oleh peneliti dilakukan berdasarkan perhitungan rumus Slovin, yaitu:

$$
\frac{\mathrm{N}}{1+\mathrm{N}(\mathrm{e})^{2}}
$$

Keterangan:

$\mathrm{n}$ = Jumlah sampel yang dibutuhkan

$\mathrm{N}=$ Jumlah populasi

$\mathrm{e}=$ Tingkat kesalahan (tingkat kesalahan $10 \%$ dengan tingkat kepercayaan $90 \%)$

Berdasarkan rumus Slovin di atas, maka sampel yang akan diambil pada penelitian ini berjumlah. Berdasarkan hasil hitungan di atas, maka jumlah responden yang digunakan pada penelitian ini sebanyak 100 orang.

\section{HASIL DAN PEMBAHASAN}

\section{Karakteristik Wisatawan}

Dari 100 orang responden wisatawan, 52 orang di antaranya merupakan wanita dan 48 orang pria. Dapat disimpulkan bahwa jumlah wisatawan wanita lebih banyak daripada wisatawan pria, hal ini juga terjadi dalam penelitian Dewanto (2016) tentang nilai ekonomi di objek wisata Taman Kota menggunakan metode biaya perjalanan. Usia responden wisatawan yang mengunjungi objek wisata Pemandian Air Panas Walini terdiri dari berbagai usia dari 21 hingga lebih dari 51 tahun dengan mayoritas responden berusia 41-50 tahun. Hal ini serupa dengan penelitian yang dilakukan oleh Samsudin (2013) tentang valuasi nilai ekonomi Taman Nasional Bunaken menggunakan metode biaya perjalanan dimana rentang usia responden 
wisatawannya yaitu 19-50 tahun. Tingkat pendidikan responden pada penelitian ini yaitu lulusan SD berjumlah 3 orang, lulusan SMP sebanyak 14 orang,lulusan SMA sebanyak 39 orang, lulusan D3 atau S1 sebanyak 43 orang, dan lulusan pascasarjana sebanyak 1 orang. Tingkat pendidikan D3/S1 dengan jumlah responden paling banyak juga terjadi pada penelitian Effendi (2015) tentang nilai ekonomi di wisata Pulau Tangkil, Provinsi Lampung menggunakan biaya perjalanan, dimana dari 105 orang responden, 78 di antaranya memiliki tingkat pendidikan terakhir perguruan tinggi.

Sebagian besar responden wisatawan bekerja sebagai pegawai swasta dengan jumlah 34 orang dan yang lainnya adalah pelajar atau mahasiswa, PNS, wiraswasta, ibu rumah tangga, buruh, TNI, dan sopir ojek online. Penelitian Al-Khoiriah (2017) tentang evaluasi ekonomi Taman Wisata Pulau Pahawang dengan pendekatan biaya perjalanan menunjukkan jumlah pegawai swasta lebih dominan yaitu sebanyak 18 dari 40 orang jumlah respondennya. Untuk tingkat pendapatan, sebagian besar responden wisatawan memiliki pendapatan lebih dari Rp 4.000.000,- dengan jumlah 61 orang sementara responden wisatawan lainnya memiliki pendapatan antara Rp 1.000.000 - Rp 4.000.000, -. Serupa dengan penelitian Dewanto (2016) tentang nilai ekonomi pada wisata Taman Kota menggunakan metode biaya perjalanan dimana 36 dari 84 orang respondennya memiliki pendapatan lebih dari Rp 2.000.000,-. Berdasarkan asal daerahnya, 50 dari 100 orang responden wisatawan berasal dari Kota Bandung dan 50 orang responden lainnya berasal dari luar Kota Bandung.Hal ini berarti bahwa wisatawan cenderung mencari destinasi wisata di lokasi yang baru demi mencari hiburan, mengurangi kepenatan, dan kejenuhan dari rutinitas kesehariannya (Arniawati, 2017).

Mayoritas responden wisatawan yang datang bersama keluarga berjumlah 76 orang, sedangkan responden wisatawan yang datang bersama kelompok berjumlah 20 orang dan datang sendiri 4 orang. Pada penelitian Natio (2018) tentang analisis nilai ekonomi Pemandian Armaya menggunakan pendekatan biaya perjalanan diketahui bahwa 147 jumlah responden yang datang bersama keluarga juga merupakan jenis kedatangan dengan jumlah terbanyak yaitu sejumlah 95 dari 100 orang responden. Sebanyak 96 dari 100 orang responden wisatawan datang ke objek wisata Pemandian Walini menggunakan kendaraan pribadi, baik itu kendaran roda dua ataupun kendaraan roda empat. Hal yang serupa terjadi pada penelitian Sinaga (2018) tentang penilaian ekonomi dan strategi pengelolaan Wana Wisata Kawah Putih dengan metode biaya perjalanan, dimana jenis kendaraan yang paling banyak digunakan wisatawan adalah jenis kendaraan pribadi. Untuk frekuensi kunjungan, responden wisatawan yang baru pertama kali mengunjungi objek wisata Pemandian Air Panas Walini berjumlah sebanyak 18 orang, sementara yang berkunjung sebanyak 2 kali berjumlah 28 orang; 3 kali berjumlah 14 orang; 4 kali sebanyak 16 orang sedangkan yang lebih dari 4 kali kunjungan berjumlah 24 orang. Dari hasil tersebut terlihat bahwa mayoritas responden telah melakukan kunjungan ke Pemandian Walini sebanyak 2 kali. Pada penelitian Wanti (2014) tentang analisis nilai ekonomi Kebun Kina Bukit Unggul dengan metode biaya perjalanan, dimana jumlah responden yang sudah mengunjungi objek wisata 1-2 kali memiliki jumlah paling besar yaitu 37 dari 60 orang responden.

Sebagian besar responden wisatawan mengetahui objek wisata dari teman atau keluarga. Dari 100 responden, hanya 8 orang responden wisatawan yang mengetahui objek wisata Pemandian Air Panas Walini dari media elektronik. Hal ini juga terjadi pada penelitian Natio (2018) tentang nilai ekonomi di Pemandian Armaya, dimana mayoritas respondennya mengetahui keberadaan informasi objek wisata dari teman atau keluarga. Mayoritas responden wisatawan mengunjungi objek wisata Pemandian Air Panas Walini dengan tujuan berlibur yaitu berjumlah 97 orang dan yang lainnya datang dengan tujuan berobat. Jumlah responden yang lebih banyak memiliki tujuan kunjungan berlibur serupa dengan penelitian yang dilakukan oleh Sinaga (2018) tentang nilai ekonomi dan strategi pengelolaan yang dilakukan di Wana Wisata Kawah Putih, 
Ciwidey.

\section{Faktor-Faktor Yang Mempengaruhi Frekuensi Kunjungan Wisatawan}

Untuk menghitung nilai ekonomi, analisis faktor-faktor yang mempengaruhi kunjungan wisata perlu dilakukan dengan menggunakan regresi linier berganda. Sebelum melakukan analisis regresi linier berganda, perlu dipastikan bahwa model regresi sudah lulus ketiga uji asumsi klasik, yaitu uji normalitas untuk mengetahui apakah model regresi terdistribusi secara normal, uji multikolonieritas untuk mengetahui adakah korelasi antara variabel terikat dan variabel bebas, dan uji heterokedastisitas untuk mengetahui apakah terjadi ketidaksamaan varian dari residual pengamatan ke pengamatan lain dalam model regresi (Ghozali, 2011).

Berdasarkan hasil regresi pada
Tabel 1 fungsi frekuensi kunjungan wisata Pemandian Air Panas Walini yang diperoleh adalah sebagai berikut:

$$
\begin{aligned}
\mathrm{Y}= & 3,071-0,265 \mathrm{X}_{1}+0,100 \mathrm{X}_{2}-0,111 \\
& \mathrm{X}_{3}-0,130 \mathrm{X}_{4}-0,151 \mathrm{X}_{5}+0,202 \mathrm{X}_{6} \\
& +\varepsilon \ldots \ldots \text { (2) }
\end{aligned}
$$

$$
\begin{aligned}
& \text { Keterangan: } \\
& \begin{aligned}
\mathrm{Y}= & \text { Frekuensi kunjungan (kali/tahun) } \\
\mathrm{X}_{1}= & \text { Jarak tempat tinggal dengan objek } \\
& \text { wisata (km) } \\
\mathrm{X}_{2}= & \text { Usia (tahun) } \\
\mathrm{X}_{3}= & \text { Pendidikan (tahun) } \\
\mathrm{X}_{4}= & \text { Pendapatan (Rp) } \\
\mathrm{X}_{5}= & \text { Biaya perjalanan (Rp) } \\
\mathrm{X}_{6}= & \text { Jumlah rombongan (orang) } \\
\text { bo }= & \text { Konstanta } \\
\beta_{1-} \beta_{6}= & \text { Koefisien regresi untuk faktor 1-6 } \\
\varepsilon & =\text { Error term }
\end{aligned}
\end{aligned}
$$

Tabel 1. Hasil Regresi Fungsi Permintaan

\begin{tabular}{|l|c|c|c|}
\hline \multicolumn{1}{|c|}{ Prediktor } & Koefisien & P value & VIF \\
\hline Constant & 3,071 & 0,000 & \\
\hline Jarak Tempat Tinggal & $-0,265$ & $\mathbf{0 , 0 1 9} *$ & 1,522 \\
\hline Usia & 0,100 & 0,337 & 1,341 \\
\hline Pendidikan & $-0,111$ & 0,308 & 1,458 \\
\hline Pendapatan & $-0,130$ & 0,209 & 1,299 \\
\hline Biaya Perjalanan Total & $-0,151$ & 0,153 & 1,355 \\
\hline Jumlah Rombongan & 0,202 & $\mathbf{0 , 0 5 0} * *$ & 1,277 \\
\hline $\mathbf{R}^{2}$ & 0,250 & & 1,788 \\
\hline Adj. $\mathbf{R}^{\mathbf{2}}$ & 0,202 & Durbin Watson & \\
\hline
\end{tabular}

Tabel 1 menunjukkan bahwa nilai Adjusted $R$ Square (Adj. $\mathrm{R}^{2}$ ) atau koefisien determinasi adalah sebesar 0,202 atau 20,2\%. Nilai koefisien determinasi ini menunjukkan seberapa besar variabel terikat dapat dijelaskan oleh variabelvariabel bebas yang terdapat di dalam model regresi. Sementara $79,8 \%$ sisanya dijelaskan oleh variabel-variabel lain yang tidak dimasukkan ke dalam model. Uji parsial (uji T) juga telah dilakukan terhadap masing-masing variabel bebas. Uji T dilakukan untuk mengetahui seberapa jauh variabel bebas berpengaruh secara individual terhadap variabel terikat (Ghozali, 2011). Berikut penjelasan pengaruh dari masing-masing variabel:

\section{Jarak Tempat Tinggal}

Berdasarkan hasil analisis regresi linier berganda, jarak tempat tinggal memiliki pengaruh negatif terhadap frekuensi kunjungan dengan besaran nilai koefisiensi 0,265. Jarak tempat tinggal berpengaruh secara signifikan terhadap frekuensi kunjungan. Pada penelitian Wanti (2014) menunjukkan jarak tempuh memiliki pengaruh negatif terhadap permintaan wisata Kebun Kina Bukit Unggul Kabupaten Bandung.

\section{Usia}

Variabel usia berpengaruh positif terhadap frekuensi kunjungan, jadi apabila 
terjadi peningkatan usia dengan asumsi variabel lainnya tetap maka akan terjadi peningkatan frekuensi kunjungan sebesar $0,100 \%$. Usia tidak berpengaruhsecara signifikan terhadap frekuensi kunjungan. Pada penelitian yang dilakukan Natio (2018), usia juga memiliki pengaruh positif terhadap frekuensi kunjungan dengan nilai koefisien 0,038 .

\section{Pendidikan}

Variabel pendidikan memiliki pengaruh negatif terhadap frekuensi kunjungan, jadi apabila terjadi peningkatan pendidikan dengan asumsi variabel lainnya tetap, maka akan terjadi penurunan frekuensi kunjungan sebesar $0,111 \%$. Pendidikan tidak berpengaruh secara signifikan terhadap frekuensi kunjungan. Pengaruh negatif variabel pendidikan juga terjadi pada penelitian Sunarti (2018), di mana nilai koefisinnya sebesar 0,061 .

\section{Pendapatan}

Variabel pendapatan memiliki pengaruh negatif terhadap frekuensi kunjungan, jadi apabila terjadi kenaikan pendapatan, maka akan terjadi penurunan frekuensi kunjungan sebesar 0,130\%. Pendapatan tidak berpengaruh secara signifikan terhadap frekuensi kunjungan. Pada penelitian Natio (2018), tingkat pendapatan memiliki pengaruh positif terhadap jumlah kunjungan wisatawan pada wisata Pemandian Air Panas Armaya.

\section{Biaya Perjalanan}

Variabel biaya perjalanan memiliki pengaruh negatif terhadap frekuensi kunjungan, jadi apabila terjadi kenaikan biaya perjalanan maka akan terjadi penurunan frekuensi kunjungan sebesar $0,151 \%$. Biaya perjalanan tidak berpengaruh secara signifikan terhadap frekuensi kunjungan. Pengaruh biaya perjalanan yang tidak signifikan juga terjadi pada penelitian Wanti (2014) dimana biaya perjalanan dan tingkat pendidikan tidak memiliki pengaruh yang signifikan terhadap permintaan wisata Kebun Kina Bukit Unggul.

\section{Jumlah Rombongan}

Jumlah rombongan memiliki pengaruh positif terhadap frekuensi kunjunga, jadi apabila terjadi kenaikan jumlah rombongan maka akan terjadi peningkatan frekuensi kunjungan sebesar 0,202\%. Jumlah rombongan berpengaruh secara signifikan terhadap frekuensi kunjungan. Selain uji T, uji $\mathrm{F}$ juga sudah dilakukan pada model regresi ini. Uji $F$ dilakukan untuk mengetahui tingkat signifikansi variabel bebas secara bersama-sama atau simultan berpengaruh terhadap variabel terikat (Ghozali, 2011). Jika nilai signifikansi $<0,05$ maka artinya variabel bebas secara simultan berpengaruh terhadap variabel terikat. Tabel 24 menunjukkan bahwa nilai signifikansi yang diperoleh yaitu $0,000<0,05$, hal ini menunjukkan bahwa variabel jarak tempat tinggal, usia, pendidikan, pendapatan, biaya perjalanan, dan jumlah rombongan berpengaruh secara simultan terhadap frekuensi kunjungan wisatawan. Pada penelitian Priambodo (2016) tentang nilai ekonomi Agrowisata Kota Batu, variabel bebas seperti biaya perjalanan, usia, tingkat pendidikan, tingkat pendapatan, jarak tempuh, jumlah rombongan, jenis kelamin, dan status perkawinan berpengaruh terhadap variabel terikatnya yaitu jumlah kunjungan wisatawan.

\section{Nilai Ekonomi}

Nilai ekonomi dilakukan dengan pendekatan Individual Travel Cost Method (ITCM). Berbeda dengan Zona Travel Cost Method, pendekatan ini tidak membutuhkan rata-rata biaya perjalanan untuk memperoleh nilai ekonomi (Fauzi, 2006). Dalam metode ini, penghitungan surplus konsumen atau WTP wisatawan harus dilakukan terlebih dahulu guna memperoleh nilai ekonomi objek wisata. Hasil perhitungan nilai ekonomi dapat dilihat pada Tabel 2.

Berdasarkan hasil wawancara dengan 100 orang responden, jumlah kunjungan responden dalam satu tahun terakhir sebanyak 137 kali. Koefisien biaya perjalanan yang didapat yaitu sebesar 0,151. Surplus konsumen diperoleh dengan kunjungan masing-masing responden dibagi dua lalu dikali koefisien biaya perjalanan. Nilai surplus konsumen wisatawan Pemandian Air Panas Walini diperoleh sebesar Rp 33.112 per orang per kunjungan.

Nilai ekonomi Pemandian Air Panas Walini diperoleh dari hasil perkalian surplus konsumen individu per kunjungan dengan jumlah kunjungan 2019 hingga 
akhirnya diperoleh nilai ekonomi sebesar Rp 6.394.456.992 per tahun. Hal ini dapat diartikan bahwa objek wisata Pemandian Air Panas Walini memiliki manfaat besar sebagai penghasil jasa. Nilai ekonomi dapat menjadi lebih besar lagi dengan adanya penambahan fasilitas agar pengelolaan objek wisata dapat dilakukan secara maksimal. Besaran nilai ekonomi ini juga menunjukkan bahwa wisatawan masih memiliki minat untuk mempertahankan keberadaan objek wisata.

Tabel 2. Perhitungan nilai ekonomi Pemandian Air Panas Walini

\begin{tabular}{|l|c|l|}
\hline KETERANGAN & NILAI & SATUAN \\
\hline Jumlah Responden (a) & 100 & Orang \\
\hline Jumlah Kunjungan Responden (b) & 137 & Kali/Tahun \\
\hline Jumlah Kunjungan Tahun 2019 (c) & 193.116 & Kali/Tahun \\
\hline Koefisien Biaya Perjalanan (d) & 0,151 & Satuan \\
\hline Surplus Konsumen (e) $=$ b/2d & 4.536 .424 & Rupiah \\
\hline Surplus Konsumen /Individu/Kunjungan (f) = e/b & 33.112 & Rupiah \\
\hline Nilai Ekonomi (g)= f X c & 6.394 .456 .992 & Rupiah \\
\hline
\end{tabular}

\section{KESIMPULAN}

Wisatawan yang melakukan kegiatan wisata di Pemandian Air Panas Walini didominasi oleh wanita. Sebagian besar wisatawan berusia 41-50 tahun, bekerja sebagai pegawai swasta dan berasal dari Kabupaten atau Kota Bandung serta Jabodetabek dan datang bersama keluarganya.

Dari analisis regresi diperoleh hasil bahwa jarak tempat tinggal dan jumlah rombongan berpengaruh secara signifikan terhadap frekuensi kunjungan selama setahun. Berdasarkan hasil analisis yang dilakukan, estimasi nilai ekonomi objek wisata Pemandian Air Panas Walini dengan pendekatan biaya perjalanan adalah sebesar Rp 6.394.456.992 per tahun dengan surplus konsumen per kunjungan sebesar Rp 33.112. Besaran nilai ekonomi ini menunjukkan bahwa wisatawan masih berminat untuk mempertahankan keberadaan objek wisata Pemandian Air Panas Walini.

\section{DAFTAR PUSTAKA}

Al-Khoiriah, Rofiiqoh, Fembriarti Erry dan Irfan Affandi. 2017. Evaluasi Ekonomi dengan Metode Travel Cost pada Taman Wisata Pulau Pahawang
Kabupaten Pesawaran. JIIA. 5(4).

Amalia, Ulfah Suci dan Ernah. 2017.THE Analysis Of Economic Value On Irrigation Utilizationatrice Farming In Buahdua District, Sumedang Regency, West Java. AGROLAND: The Agricultural Sciences Journal. December 4 (2) 89 - 97

Arniawati, Safril Kasim dan Rahmawati Anshar. 2017. Analisis Jasa Lingkungan Ekowisata Air Terjun Lahundape di Kawasan Tahura NipaNipa. Jasa Lingkungan Ekowisata Air Terjun Lahundape. 3(1).

BPS. 2017. Badan Pusat Statistik Kota Bandung.

Dewanto, Bayu, Defri Yoza dan Tuti Arlita. 2016. Nilai Ekonomi Wisata Taman Kota Berdasarkan Metode Biaya Perjalanan (Travel Cost Methode) Di Pekanbaru. Jom Faperta Ur. 3(2).

Effendi, Ahmad, Samsul Bakri \& Rusita. 2015. Nilai Ekonomi Jasa Wisata Pulau Tangkil Provinsi Lampung Dengan Pendekatan Metode Biaya Perjalanan. Jurnal Sylva Lestari. 3 (3).

Fauzi, Akhmad. 2006. Ekonomi Sumber Daya 
Alam dan Lingkungan. Jakarta: Gramedia Pustaka Utama.

Ghozali, Imam. 2011. Aplikasi Analisis Multivariate dengan Program IMB SPSS 25. Semarang: Badan Penerbit Universitas DiponegoroLestari, Oktaviani Fuji. 2017. Analisis Nilai Ekonomi Objek Wisata Air Terjun Tanjung Belit Di Kecamatan Kampar Kiri Hulu Kabupaten Kampar dengan Pendekatan Metode Biaya Perjalanan. Jom Fekon. 4(1)

Natio, Lisa Victoria. 2018. Analisis Nilai Ekonomi di Pemandian Armaya, Sungai Belawan Kecamatan Kutalimbaru. [Skripsi]. Sumatera Utara: Universitas Sumatera Utara.

Reynalto, Alfret dan Ernah. 2019. Factors Affecting the Export of Crude Palm Oil Indonesia. AGROLAND: The Agricultural Sciences Journal. December 6 (2) 89 - 99

Samsudin, Nurhayati, Budiono dan Wawan Hermawan. 2013. Valuasi Nilai Ekonomi Taman Nasional Bunaken : Aplikasi Travel Cost Method (TCM). Bandung: Universitas Padjadjaran.
Sinaga, Maria Else Avrelia. 2018. Penilaian Ekonomi dan Strategi Pengelolaan Wana Wisata Kawah Putih di Kabupaten Bandung, Jawa Barat. [Skripsi]. Bogor: Institut Pertanian Bogor.

Sugiyono. 2017. Metode Penelitian Kuantitatif. Bandung : AlfabetaSunarti, Syukur Umar dan Andi Sahri Alam. 2018. Nilai Ekonomi dan Kunjungan Objek Wisata Alam Air Terjun Desa Nupabombakecamatan Tanantovea Kabupatendonggala. Jurnal Warta Rimba. 6(4).

Wanti, Listiana Widya, Yusman Syaukat dan Bambang Juanda. 2014. Analisis Nilai Ekonomi Wisata Kebun Kina Bukit Unggul Kabupaten Bandung. Jurnal Ekonomi Pertanian, Sumberdaya Dan Lingkungan. 1(2).

World Trade Organization. 2014. Pengaruh Pariwisata terhadap Pertumbuhan Ekonomi. Diambil dari https://www.ilo.org/wcmsp5/groups/pu $\underline{b} \quad \underline{\text { ic/---asia/---ro-bangkok/---ilo- }}$ jakarta/documents/publication/wcms_2 0 9132.pdf [15 Oktober, 2019] 